\title{
Linkage between commuting time and sickness absence in the context of China: transmission channels and heterogeneous effects
}

\author{
Wang Zicheng \\ Jinan university \\ Liu Jiachun \\ Jinan University \\ Murong Guo ( $\sim$ 495233843@qq.com ) \\ Renmin University of China
}

\section{Research}

Keywords: Commuting time, Sickness absence, Mechanism, Health-related status, Work efforts, Heterogeneous effects

Posted Date: March 18th, 2020

DOI: https://doi.org/10.21203/rs.3.rs-17906/v1

License: (c) (i) This work is licensed under a Creative Commons Attribution 4.0 International License. Read Full License 


\section{Abstract}

Background Most of employees in urban China have experienced a heavy commuting burden,which has become an urgent issue that should be solved in the process of new urbanization strategy. However, not only has the exploration of relationship between the commuting and sickness absence been still scant in China, but also there is no discussion made to analyze the mechanism linking the commuting time and sickness absence. To address these gaps, this study firstly investigates the commuting-absence effect as well as the potential transmission channel between them. Methods Using a unique dataset of 2013 Matched Employer-Employee Survey (CMEES) in China, we apply the zero-inflated negative binomial model to explore the nexus between the commuting and sickness absence. To discuss the potential mechanism linking commuting and sickness absence in the context of China, the estimations of the commuting on health-related outcomes and work efforts are performed by the OLS and Logit regression to discuss the mechanism. Results The empirical results reveal that the commute has a positive effect on sickness absence, while it is still robust against several specifications. More importantly, the commuting-absence effect is mainly transmitted through health-related outcomes of employees, whereas we find no clear evidence supporting the shirking behaviors. Additionally, the heterogeneous effects of commuting-absence are differentiated across the Hukou status, gender, transportation modes, scale of cities and types of enterprises. Conclusion The longer commute induces to lower productivities through the sickness absence, that is, the longer journey from home to work is positively related with the increasing sickness absence, which keeps in consistency with previous studies. And the potential effect of commute-sickness absence is mainly transmitted through their health-related outcomes. Additionally, the impacts of commute time on sickness absence are differentiated across the Hukou status, gender, transportation modes, scale of cities and types of enterprise.

\section{Background}

Commuting is an indispensable part of daily life for millions of people worldwide[1]. A large array of previous studies focused on the relationships between the commuting and the employees' labor market performance [2-4]. With negative externalities of the sickness absence, the nexus between the commuting and sickness absence has also attracted extensive attentions $[2,5]$.

Based on the theory of new welfare economics, long commute is viewed as an activity of time-consumption, which is related with poor psychological and physical health outcomes [6-8]. Accordingly, the leisure time of employees for health-promoting plans, such as physical activities, relaxation and social participation may be crowded out by the longer commuting time [9]. In addition, while the leisure could be substituted for shirking by each other, there is more likely for shirking behaviors among those employees with a longer commute time [10]. It implies that with the decreasing cost of absence, a longer commuting may lead to more benefit from their absence to ask for more leisure, which could be used for other purposes rather than for work [5]. Therefore, asking for "sickness" leave could be regarded as a result of rational decision.

There is also no consensus reached in empirical studies. It is a common belief that longer journeys may induce more sickness absence. A body of evidences from developed markets have confirmed that a longer commuting might increase the likelihood of illness-related absence [2, 5, 11-12], but several studies also reveal that there was no evidence supporting the commute-absence effect $[5,13]$. More importantly, some researches provide the evidence on heterogeneous commute-absence effects. Using data from the Panel Study of Income Dynamics for the years 2011, 2013, and 2015, Gimenez-Nadal et al. (2018) found that the daily commute is associated with men's sick-day absences, while it has no significant effect on women [14]. Similarly, Karlström and Isacsson (2010) 
also pointed out that commuting time only has a positive effect on sickness absence of women with lower wages [15].

Additionally, several studies from non-western countries also show clear evidences that commute time are linked with bad health status. Using a large and unique nationally representative sample in Brazil, Oliveira et al. (2015) drew the conclusion that individuals with more than one hour of commuting are more likely to be in poor health status [16]. Applying the Seoul survey data collected between 2006 and 2015, Jun et al. (2019) also revealed a negatively relationship between commuting time and subjective well-being [17]. A survey was conducted in Tokyo for school teachers by Nomoto et al. (2015), which also demonstrated that long-time commuters are more likely for less sleep and exercise [18].

With the rapid urbanization and increasing ownership of private vehicle, most of employees in urban China have experienced a heavy commuting burden [8], an increasing amount of research has focused on the nexus between commuting and urban residents' subjective well-being [8,19-21]. But the discussion on commute-sickness absence effect is still scant in those non-western countries, which should be further explored in the future.

In sum, previous studies have two limitations as follows. Firstly, it is important to be aware that absence due to sickness is a multi-factorial phenomenon [22-23]. Most of studies were carried out in the European developed markets, whereas the discussion in the non-western or undeveloped context is still unexplored. Another limitation is that the mechanism linking the commuting and sickness is still unclear, whereas the debate whether the commuting-absence effect is transmitted through health-related outcomes or shirking behaviors is underexplored as well.

To fill these gaps, this study attempts to address two issues: whether commute time is positively related with sickness absence or not? If it does, what is the potential mechanism linking the commute time and sickness absence?

This study may contribute to the exiting studies in several distinct ways.

Firstly, following Goerke and Lorenz(2017)[5], a unique dataset (CMEES) and the zero-inflated negative binomial model are firstly applied to explore the nexus between commuting and sickness absence in China context.

Secondly, the two potential transmission channels linking the commuting and sickness absence are discussed in China context by estimating the effect of commuting on health-related outcomes and work efforts.

Thirdly, the heterogeneous commuting-absence effects with respect to Hukou status, gender, patterns of commuting, scale of cities and types of companies are taken into full consideration within the context of China.

\section{Materials And Methods}

\section{Data source}

We use the data from China's Matched Employer-Employee Survey (CMEES), which is conducted by the School of Labor and Human Resources, Renmin University. Using the two-stage method of stratified sampling, the dataset was selected from an enterprise listing set up on the basis of the 2008 national economic census data. The sample was collected from managers who were responsible for employment relations or personnel matters in the private 
and public sector companies with 20 or more staffs. If a sampled enterprise refused to response, it would be replaced by another company with the same firm size in the same industry.

The commute time is only available in the wave of 2013. There are 4,532 employees from 444 enterprises and 12 cities covered in 2013 CMEES. The CMEES not only collects the rich information on the characteristics of companylevel, demographic and employment traits for employees, but also provides the detailed information about both days absent for sickness and the commuting time, which is appropriate to discuss the effect of the commuting on sickness absence.

\section{Ethnics Statement}

This study is a secondary analysis based on the data from the CMEES conducted by School of Labor and Human

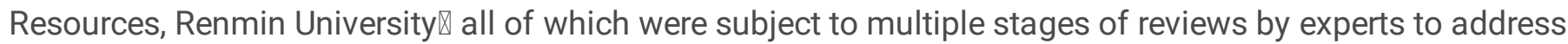
methodological, ethical and legal issues related to data collection. Final approvals of all CMEES surveys were required from the Research Ethics Committee of Renmin University to ensure that the data collection complied with ethical requirement according to the Statistics Act.

\section{Explanatory and outcome variables}

The outcome variable is the annual number of days absent from work due to sickness, which derives from the following items in the survey "In the past year, how many days have you asked for a leave due to illness?"

The focal variable is the commuting time, which is described as minutes spent in one-way daily commute.

According to previous studies, controlled variables are divided into three sets: individual-level variables, companylevel variables as well as city-level variables.

Individual-level variables consist of age, age squared, male (ref=female), education years, education years squared, migration status (ref=non-migrant), occupation categories (ref=ordinary worker), job strain, overtime, training, job tenure, job security, injure, wage (log). Company level variables incorporate company type (ref=domestic private enterprise) and sector (ref=other non-manufacture industry). City-level variables has three categories, including firsttier cites, second-tier cites and third-tier cities.

\section{Econometric model}

The number of days absent for sickness is a count variable $(0,1,2,3$, and so on), the ZINB model may be more appropriate for this study. The countfit function in Stata software was used to make goodness-fit test of all four count models. All the fit statistics including AIC, BIC, and Vuong test proves that the ZINB is the best model for this study (As depicted Table 1).

The ZINB regression includes three steps. First, a Logit model is applied for the "certain zero" cases to predict whether an employee would be in this group or not. Then, an NB model is used for the prediction of the counts for those workers who are not certain zeros. Finally, all two models are pooled.

\section{Results}

\section{Descriptive statistics}


Table 2 shows the descriptive statistics. The average number of days absent for sickness is nearly 2.46 , whereas about $60 \%$ of employees have not been absent for illness and only $1.9 \%$ of them are absent over 30 days. The mean of one-way commuting time is about 26 minutes, and the maximum value reaches at 120 minutes. Most of urban workers in China suffer heavy commute burden, while there are $40 \%$ of commuters with a daily commute over 26 minutes. Besides, $34.31 \%$ of them have a journey between 10 minutes and 26 minutes, but only $25.89 \%$ of them commute less than 10 minutes.

\section{Benchmark results}

As shown in Table 3, Model (1) only includes the focal independent variable of commuting time without controlled factors. Models (2), Models (3) and Model (4) adds individual characteristics, company traits and city-level variables step by step, and all regressions are used robust standard errors to adjust for the heterogeneity in the model.

The results are presented in Model (1). Without controlling for individual demographic characteristics, the commute plays a significantly positive role in sickness absence. After adding controls into Model 1, such as individual characteristics, job-related traits, company types, sectors and city scale, the commute also has a significantly positive effect on sickness absence (as shown in Model (2) -Model (4)).

\section{Robust checks}

Several robust checks are performed to verify the sensitivity of the main findings, as shown in Table 4. In Model (5), it applies the same baseline model through exclusive observations whose absenteeism was more than 60 days during the past year. To correct the measurement error, we also defined sickness absence as a dummy variable (it equals 1 if the individual took sick leave during the past year) to give an additional analysis of the commuteabsenteeism relationship in model (6). Similarly, we also divided commuters into three subgroups to estimate the commute-absenteeism effect in model (7), where the commuters with less than 10 minutes commute (i.e., $0 \leq \mathrm{CT} \leq 10$ minutes) are defined as short-commuters. The journey between 10 minutes and less than 26 minutes are middle-time commute (i.e., $10<\mathrm{CT} \leq 26$ minutes), while those who travel over 26 minutes are long-time commuters (i.e., CT>26minutes). Model (8) is to re-estimate for those who have not been injured at work during the past year; while Model (9) excludes observation of individuals whose medical expenditure in the past year was more than 10,000 Yuan. In Model (10), the variables of the transportation modes are incorporated, the active mode refers to those who walked or cycled to work, while passive mode includes those who drove cars or used public transportation.

As shown in Table 4, there is a robust positive association between commute and sickness absence against several specifications.

\section{Mechanism analysis}

There are two possible mechanisms linking the commute and sickness absence. One is that longer commute might weaken employees' health status, which induces involuntary or unavoidable absenteeism; another is that commuting may induce shirking behaviors, thereby increasing the probability of the voluntary or avoidable absenteeism. The health-related status, such as subjective health indexes (self-rated health status, degree of depression) and objective health indicators (BMI index, obesity, and annual medical expenses) are incorporated as outcomes in Model (11) - Model (15). With the dataset unavailable, we apply the length of weekly overtime and 
weekly overtime probability (whether the weekly work time is above 40 hours or not ) as proxies for work efforts to check the potential mechanism of shirking behaviors in Model (16) and Model (17).

As shown in Table 5, a longer commuting is associated with poorer self-rated health status and a higher degree of psychological depression, and it also is highly related with an increase of their BMI index, annual medical expenses as well as the risk of obesity. However, results reveal that the commuting has no significant effect on both the overtime length and probability of overtime, that is, the mechanism of commute-absence effect through the shrinking behaviors is not confirmed (see model (16)-(17) in Table 5).

\section{Heterogeneous effects}

In this section, we attempt to estimate heterogeneous effects of commutes on absenteeism for sickness with respect to Hukou status, gender, transportation mode, the scale of cities, the type of enterprises and Hukou status.

The estimations as shown in Table 6 indicate that commute is positively associated with migrants' sickness absence, but has no significant effect on urban citizens. Similarly, commute only has a positive influence on men's absence, while has no significant influence on women. As for the transportation mode, no significant evidence is found from both active and positive groups. A significant commute-absence effect is captured in the first-tier city group, while the associations linking commute time and sickness absence are not significant in the second-tier and third-tier city. Commute has a negative effect on the employees in foreign-owned enterprise, and it also produces a positive influence on the workers in domestic private enterprises, but has no significant effect on the employees in state-owned enterprise.

\section{Discussion}

It is apparent that not only is the relationship between commuting and sickness absence theoretically ambiguous, but also it has still reached inconsistency in empirical studies. The results in benchmark demonstrated that employees might incline to ask for ill-related absence for nearly 1 day (exp (0.0038)), with an additional increase of 1 minute, and it is consistent with the findings by Van and Gutiérrez-i-Puigarnau (2011), Goerke and Lorenz $\varangle 2017 \rrbracket$,which also confirmed a positive nexus between commute and sickness absence[2, 5]. This result is still robust against several specifications including excluding observations, correcting the measurement error, incorporating transportation modes.

The results from mechanism analysis reveal that longer commuting is associated with poorer subjective and objective health status. It is consistent with previous evidence that commuting has been linked to negative healthrelated outcomes $[8-9,24]$. In this scenario, health-related outcomes do act as an important transmission channel linking the relationship between the commuting and sickness absence. It is in line with Gimenez-Nadal et al. (2018) [14], which also depict the association between commuting and workers' health-related outcomes. This finding implies that more time spent on commute might break the work-life balance among employees and tend to push more burdens on both objective and subjective health status, including a combination of the tension, tiredness, depression, irregular diet and so on, which might lead to the greater likelihood of involuntary or unavoidable sickness absenteeism and lower their productivity.

The mechanism analysis also demonstrates that commute has no significant influence on work efforts, which implied that commuting cannot increase the probability of shirking behaviors. It is contrary with Goerke and Lorenz (2017), which pointed out that commuting time are positively related with working overtime [5]. The potential 
explanation may be that overtime is a common phenomenon in China [25]. The premium for overtime is an important part of the salary, and the employees have to work overtime for additional premiums as well as the basic compensation [26]. For another, Chinese employers are more likely to overburden their employees [27], and working overtime has to be a necessary routine to meet the employer's claims or expectation. Thus, the longer commuters in China are less likely to show shrinking behaviors not only due to the financial reasons, but also owing to the requirement by employers.

The estimation of heterogeneous effects shows more interesting results. Commute has a positive effect on migrants' sickness absence, but has no significant effect on urban citizens. It is in contrast with the finding by Chia (1988), which suggested that migrants in Singapore have a higher possibility of sickness absence than their local counterparts [28]. The potential explanation is that rural migrants' access to public health service is legally restricted by the Hukou system [29]. Once they get sick, they have to choose a private clinic nearby rather than a formal hospital to get medical service [30]. These unregulated private clinics usually fail to provide official certificates for migrants to obtain sick leave permission. Without sick leave permission , these rural migrants may suffer an extra economic loss of day-off work, so they are less likely to be absent even if they are ill or uncomfortable [31].

Commute is positively related with the men's absence, while has no significant influence on women. It is consistent with Gimenez-Nadal et al. (2018), which draws the same conclusion in US [14]. This gender differential may be due to women's shorter commute times. The gender stratification is still a serious problem in China, whereas the women often bear disproportionately heavy household responsibility including housework and childcare [32-34].

Both for the passive and active modes, commuting time have positive but no significant effect on sickness absence. This finding is different against previous studies which confirmed that the active commuting is related with better health status and less sickness absence [35-37]. The possible reason may be that cycling in China may induce to worse health-status, which is different from other developed countries. Because the non-motor vehicle traffic plans and public bicycle facilities supply are ignored by the local government [38]. Thus, insufficient bicycle lanes expose cyclist to be more vulnerable in mixed traffic, which may threaten the cyclist's health by potential bikeautomobile collision [39].

Long commute produces a positive influence on sickness absence in first-tier cities, but has no significant effect in second-tier and third-tier cites. This implies that the employees in the megacity behemoths suffer more commute burden [8,40], which does more harm to their subject and objective health status. As for the enterprises differentials, our findings reveal that commute is negatively related with absence for the employees in foreign-owned enterprise, but has positive effect on absence of the employees in domestic private enterprises. The potential reasons are as follows: foreign-owned enterprise is more likely to pay transportation allowance or provide work unit bus for the long distance commuters [41], which could alleviate the employees' commuting burden. Meanwhile, foreigninvested enterprises focused more on humanistic goals, such as caring taking and welfare of employees [42]. Compared with the domestic private enterprises, they have more prone to improve the employee's quality of work life, including adopting more flexible working time plan or more comprehensive health insurance to help the long commuter to recover.

\section{Conclusion}

\section{Main findings}


With the rapid urbanization in China, to ensure the balance between work and life as well as promote the health for employees has been an urgent issue in occupational health security. This study confirms that commute time is positively related with sickness absence, whereas it is still robust against several specifications. More importantly, it further points out that health-related outcomes for employees mainly act as a transmission channel to the commuting-absence effect, but there is no clear evidence supporting the shirking behaviors. Additionally, the impacts of commutes on the absenteeism for sickness are differentiated across the Hukou status, gender, transportation modes, scale of cities and types of enterprise.

\section{Implications}

This study has several implications. Firstly, promoting the public transportation must be given priority in the process of new urbanization to relieve the heavy burden on employees with long commutes. Considering the negative externality of commuting on lower productivities, it is encouraged to provide dormitories by employers to reduce the duration of commutes.

\section{Limitation}

This study also has a certain limitation. The applied dataset of 2013 CMESS is a cross-sectional data. With the heterogeneous bias by the observed factors, the potential endogeneity might need to be addressed to explore the causality between commutes and the absenteeism for sickness in further studies.

\section{Abbreviations}

OLS: ordinary least squares; BHPS: British Household Panel Survey; CMEES: China's Matched Employer-Employee Survey; ZINB: Zero-inflated negative binomial regression; CT: commuting time.

\section{Declarations}

\section{Acknowledgements}

Not applicable.

\section{Authors' contributions}

Wang Zicheng took leadership and responsibility for the research activity planning and made substantial contributions to the conception and design of the Programme. Liu jiachun worked on the statistical analysis of the data. Guomu rong drafted the concept of the paper as well as participated in finalizing the manuscript. All authors read and approved the final manuscript.

\section{Availability of data and material}

The CMEES that support the findings of this study are available from School of Labor and Human Resources, Renmin University, but restrictions apply to the availability of these data, which were used under license for the current study, and so are not publicly available. CMEES are however available from the authors upon reasonable request and with permission of School of Labor and Human Resources, Renmin University. China's Matched Employer-Employee Survey Data Access can be contacted for more information (yuhui_li@ruc.edu.cn; df594133@163.com). 


\section{Ethics approval and consent to participate}

Not applicable

\section{Consent for Publication}

Not applicable.

\section{Competing interests}

The authors declare that they have no competing interests.

\section{Funding}

This article is funded by The National Social Science Fund of China (granted number 17BJY044 \&18ZDA081)

\section{References}

1. Holland D M. Cost of Commuting: A Review of Determinants, Outcomes, and Theories of Commuting-Related Stress. University Honors Theses. Paper 299, 2016; Available from:10.15760/honors.263

2. Van Ommeren JN, Gutiérrez-i-Puigarnau E.Are workers with a long commute less productive? An empirical analysis of absenteeism. Regional Science and Urban Economics.2011; 41(1), 1-8.

3. Gershenson S. The causal effect of commute time on labor supply: evidence from a natural experiment involving substitute teachers. Transportation Research Part A.2013; 54(2): 127-140.

4. Carta F, De Philippis M. You've come a long way, baby. Husbands' commuting time and family labour supply. Regional Science and Urban Economics.2018; 69: 25-37.

5. Goerke L, Lorenz O. Commuting and Sickness Absence (No. 946). DIW Berlin, the German Socio-Economic Panel (SOEP). 2017; Available from: http://ftp.iza.org/dp11183.pdf.

6. Roberts J, Hodgson R, Dolan P. "it's driving her mad": gender differences in the effects of commuting on psychological health. Journal of Health Economics, 2011;30(5), 1064-1076.

7. Stutzer A, Frey BS. Stress that doesn't pay: The commuting paradox. The Scandinavian Journal of Economics.2008; 110 (2):339 - 366.

8. Nie P, Sousa-Poza A. Commute time and subjective well-being in urban China. China Economic Review, 2018; 48: 188-204.

9. Hansson E, Mattisson K, Björk J, Östergren PO, Jakobsson K. Relationship between commuting and health outcomes in a cross-sectional population survey in southern Sweden. BMC public health.2011;11(1):834-834.

10. Ross, S.L. and Y. Zenou (2008), Are shirking and leisure substitutable? An empirical test of efficiency wages based on urban economics theory, Regional Science and Urban Economics, 38, 5, 498-517

11. Taylor PJ, Pocock SJ. Commuter travel and sickness absence of London office workers.British journal of preventive \& social medicine.1972; 26(3): 165-172.

12. Magee C, Stefanic N, Caputi P, Iverson D. Occupational factors and sick leave in Australian employees. Journal of occupational and environmental medicine.2011; 53(6): 627-632.

13. Hassink WH, Fernandez RM. Worker morale and effort: is the relationship causal?. The Manchester School.2018; 86(6):816-839. 
14. Gimenez-Nadal JI, Molina JA ,Velilla. Commuting Time and Sick-Day Absence of US Workers (No. 11700). IZA Discussion Papers. 2018; Available from: http://ftp.iza.org/dp11700.pdf.

15. Karlström A, Isacsson G. Is sick absence related to commuting travel time?-Swedish Evidence Based on the Generalized Propensity Score Estimator (No. 2010: 3). Swedish National Road \& Transport Research Institute (VTI).2010; Available from:

https://pdfs.semanticscholar.org/4a2c/be7b87163216fc2a1947d1642ec77f75b0bb.pdf

16. Oliveira R, Moura K, Viana J, Tigre R, Sampaio B. Commute duration and health: Empirical evidence from Brazil. Transportation Research Part A: Policy and Practice.2015; 80: 62-75.

17. Jun MJ, Kwon KH, Jeong JE. An evaluation of the value of time for commuting in Seoul: A life satisfaction approach. International journal of sustainable transportation.2019;13(10): 703-709.

18. Nomoto M, Hara A, Kikuchi K. Effects of long-time commuting and long-hour working on lifestyle and mental health among school teachers in Tokyo, Japan. Journal of human ergology.2015; 44(1):1-9.

19. Ye R, Titheridge H. A104 Impact of Individuals' Commuting Trips on Subjective Well-being-Evidence from Xi'an, China. Journal of Transport \& Health.2015; 2(2):S59.

20. Zhu Z, Li Z, Chen H, Liu Y, Zeng J. Subjective well-being in China: how much does commuting matter?. Transportation.2019; 46(4):1505-1524.

21. Sha F, Li B, Law YW, Yip PS. Associations between commuting and well-being in the context of a compact city with a well-developed public transport system. Journal of Transport \& Health.2019;13: 103-114.

22. Alexanderson K. Sickness absence: a review of performed studies with focused on levels of exposures and theories utilized. Scandinavian journal of social medicine.1998;26(4): 241-249.

23. Johns G, Nicholson N. The meanings of absence: new strategies for theory and research. Research in organizational behavior.1982; 4:127-172.

24. Künn-Nelen A. Does commuting affect health? Health economics.2016;25(8):984-1004.

25. Zeng X, Lu L, Sa'ad Umar Idris. (2005). Working time in transition : the dual task of standardization and flexibilization in China," ILO Working Papers 993766293402676, International Labour Organization. Available from: http://www.ilo.org/public/libdoc/ilo/2005/105B09_93_engl.pdf

26. Verité. Excessive overtime in Chinese supplier factories: Causes, impacts, and recommendations for action. Verité Research paper. 2004; Available from:https://www.verite.org/wpcontent/uploads/2016/11/Excessive_Overtime_in_Chinese_Factories.pdf

27. Nie P, Otterbach S, Sousa-Poza A. Long work hours and health in China. China Economic Review.2015; 33: 212229.

28. Chia KS. Sickness absence of migrant workers. Singapore medical journal.1988; 29(4): 387-392.

29. Zhao P, Howden-Chapman P. Social inequalities in mobility: the impact of the hukou system on migrants' job accessibility and commuting costs in Beijing. International Development Planning Review.2010; 32(3-4):363384.

30. Peng Y, Chang W, Zhou H, Hu H, Liang W. Factors associated with health-seeking behavior among migrant workers in Beijing, China. BMC health services research.2010; 10(1): 69.

31. Hesketh T, Jun YX, Lu L, Mei WH. Health status and access to health care of migrant workers in china. Public Health Reports.2008; 123(2):189-197.

32. Zuo J, Bian Y.Gendered resources, division of housework, and perceived fairness-A case in urban China. Journal of Marriage and Family.2001; 63(4): 1122-1133. 
33. MacPhail F, Dong XY. Women's market work and household status in rural China: Evidence from Jiangsu and Shandong in the late 1990s. Feminist Economics.2007;13(3-4): 93-124.

34. Carlsson F, He H, Martinsson P, Qin P, Sutter M. Household decision making in rural China: Using experiments to estimate the influences of spouses. Journal of Economic Behavior \& Organization.2012;84(2): 525-536.

35. Ohta M, Mizoue T, Mishima N, Ikeda M. Effect of the physical activities in leisure time and commuting to work on mental health. Journal of Occupational Health.2007;49(1):46-52.

36. Eriksson JS, Ekblom B, Kallings LV, Hemmingsson E, Andersson G, Wallin P et al. Active commuting in Swedish workers between 1998 and 2015-trends, characteristics and cardiovascular disease risk. Scandinavian Journal of Medicine \& Science in Sports. 2020; , 30(2):370-379.

37. Hendriksen IJ, Simons M, Garre FG, Hildebrandt VH. The association between commuter cycling and sickness absence. Preventive medicine.2010; 51(2):132-135.

38. Haixiao P. Evolution of Urban Bicycle Transport Policy in China. In Cycling and sustainability. 2012; Haixiao, P. (2012). Chapter 7 Evolution of Urban Bicycle Transport Policy in China. Cycling and Sustainability (Transport and Sustainability, Volume 1); Bingley, UK: Emerald Group Publishing Limited. Chapter 7:161-180.

39. Yang J, Chen J, Zhou M, Wang Z. Major issues for biking revival in urban China. Habitat International.2015; 47: 176-182.

40. Shen Q. Urban transportation in Shanghai, China: problems and planning implications. International Journal of Urban and Regional Research.1997; 21(4):589-606.

41. Zhou S, Liu Y, Kwan MP. Spatial mismatch in post-reform urban China: A case study of a relocated state-owned enterprise in Guangzhou. Habitat International.2016; 58:1-11.

42. Wang X, Bruning NS, Peng S. Western high-performance HR practices in China: A comparison among publicowned, private and foreign-invested enterprises. The International Journal of Human Resource Management.2007; 18(4):684-701.

\section{Tables}

Table 1 Tests and Fit Statistics

\begin{tabular}{|c|c|c|c|c|c|c|}
\hline PRM & & $\mathrm{BIC}=826.7$ & $\mathrm{AIC}=8.436$ & Prefer & Over & Evidence \\
\hline \multirow[t]{3}{*}{ vs } & NBRM & $\mathrm{BIC}=-17948.4$ & $\operatorname{dif}=18775.1$ & NBRM & PRM & Very strong \\
\hline & & $\mathrm{AIC}=3.557$ & $\operatorname{dif}=4.880$ & NBRM & PRM & \\
\hline & & LRX2 $=18783.4$ & prob $=0.000$ & NBRM & PRM & $p=0.000$ \\
\hline \multirow[t]{3}{*}{ vs } & ZIP & $\mathrm{BIC}=-11326.4$ & $\operatorname{dif}=12153.1$ & ZIP & PRM & Very strong \\
\hline & & $\mathrm{AIC}=5.242$ & $\mathrm{dif}=3.194$ & ZIP & PRM & \\
\hline & & Vuong $=20.01$ & prob $=0.000$ & ZIP & PRM & $p=0.000$ \\
\hline \multirow[t]{2}{*}{ vs } & ZINB & $\mathrm{BIC}=-17984.9$ & $\operatorname{dif}=18811.7$ & ZINB & PRM & Very strong \\
\hline & & $\mathrm{AIC}=3.509$ & $\operatorname{dif}=4.928$ & ZINB & PRM & \\
\hline NBRM & & $\mathrm{BIC}=-17948.4$ & $\mathrm{AIC}=3.557$ & Prefer & Over & Evidence \\
\hline \multirow[t]{2}{*}{ vs } & ZIP & $\mathrm{BIC}=-11326.4$ & $\operatorname{dif}=-6622.0$ & NBRM & ZIP & Very strong \\
\hline & & $\mathrm{AIC}=5.242$ & $\operatorname{dif}=-1.685$ & NBRM & ZIP & \\
\hline \multirow[t]{3}{*}{ vs } & ZINB & $\mathrm{BIC}=-17984.9$ & $\operatorname{dif}=36.574$ & ZINB & NBRM & Very strong \\
\hline & & $\mathrm{AIC}=3.509$ & $\operatorname{dif}=0.048$ & ZINB & NBRM & \\
\hline & & Vuong $=8.831$ & prob $=0.000$ & ZINB & NBRM & $p=0.000$ \\
\hline ZIP & & $\mathrm{BIC}=-11326.4$ & $\mathrm{AIC}=5.242$ & Prefer & Over & Evidence \\
\hline \multirow[t]{3}{*}{ vs } & ZINB & $\mathrm{BIC}=-17984.9$ & $\mathrm{dif}=6658.6$ & ZINB & ZIP & Very strong \\
\hline & & $\mathrm{AIC}=3.509$ & $\operatorname{dif}=1.733$ & ZINB & ZIP & \\
\hline & & $\mathrm{LRX} 2=6666.8$ & prob $=0.000$ & ZINB & ZIP & $\mathrm{p}=0.000$ \\
\hline
\end{tabular}


Table 2 Descriptive statistics

\begin{tabular}{|c|c|c|c|c|}
\hline & Mean & Std.Dev. & Min & Max \\
\hline \multicolumn{5}{|l|}{ Dependent variable } \\
\hline Sickness absence & 2.4556 & 7.4155 & 0 & 300 \\
\hline Sickness absence $(=0)$ & 0.5985 & 0.4903 & 0 & 1 \\
\hline Sickness absence $(\geq 30)$ & 0.0190 & 0.1364 & 0 & 1 \\
\hline \multicolumn{5}{|l|}{ Independent variables } \\
\hline Commuting time(CT) & 26.198 & 20.133 & 0 & 120 \\
\hline Long-commuter $(\mathrm{CT}>26)$ & 0.4010 & 0.4748 & 0 & 1 \\
\hline Middle-commuter $(26 \geq \mathrm{CT}>10)$ & 0.3431 & 0.4010 & 0 & 1 \\
\hline Short-commuter $(\mathrm{CT} \leq 10)$ & 0.2589 & 0.4381 & 0 & 1 \\
\hline \multicolumn{5}{|l|}{ Control variables } \\
\hline \multicolumn{5}{|l|}{$\begin{array}{l}\text { 1.Individual Level } \\
\text { (1)Personal variables }\end{array}$} \\
\hline Age & 33.224 & 9.8471 & 16 & 72 \\
\hline Male & 0.4545 & 0.4980 & 0 & 1 \\
\hline Married & 0.6652 & 0.4720 & 0 & 1 \\
\hline $\begin{array}{l}\text { Education year } \\
\text { (2)Job related traits } \\
\text { ๑Occupation categories }\end{array}$ & 13.237 & 2.8078 & 6 & 19 \\
\hline Manager & 0.2174 & 0.4125 & 0 & 1 \\
\hline Skilled worker & 0.1771 & 0.3818 & 0 & 1 \\
\hline \multicolumn{5}{|l|}{ 听ob condition } \\
\hline Job strain & 2.9101 & 1.1178 & 1 & 5 \\
\hline Overtime(hours/per week) & 3.3669 & 5.3424 & 0 & 32 \\
\hline Training time(days/per year) & 6.8506 & 15.070 & 0 & 120 \\
\hline Job tenure(years) & 5.3188 & 6.4301 & 0.5000 & 51 \\
\hline Job security & 3.6180 & 0.7765 & 1 & 5 \\
\hline Injure & 0.02339 & 0.1512 & 0 & 1 \\
\hline wage (year! & 10.338 & 0.4957 & 9.0938 & 12.429 \\
\hline \multicolumn{5}{|l|}{ 2.Company Level } \\
\hline Stated owned enterprise(SOE) & 0.1470 & 0.3541 & 0 & 1 \\
\hline Foreign owned enterprise(FOE) & 0.05841 & 0.2346 & 0 & 1 \\
\hline $\begin{array}{l}\text { Domestic private enterprise(DFE) } \\
\text { (2)Sector }\end{array}$ & 0.7928 & 0.4054 & 0 & 1 \\
\hline Manufacture & 0.3143 & 0.4643 & 0 & 1 \\
\hline \multicolumn{5}{|l|}{ 3.City Level } \\
\hline First-tier city & 0.1970 & 0.3978 & 0 & 1 \\
\hline Second-tier city & 0.6154 & 0.4866 & 0 & 1 \\
\hline Third-tier city & 0.1850 & 0.3884 & 0 & 1 \\
\hline
\end{tabular}


$\underline{\text { Table } 3 \text { Estimation of commuting time on sickness absence }}$

\begin{tabular}{|c|c|c|c|c|c|c|c|c|}
\hline & \multicolumn{2}{|c|}{ Model(1) } & \multicolumn{2}{|c|}{ Model(2) } & \multicolumn{2}{|c|}{ Model(3) } & \multicolumn{2}{|c|}{ Model(4) } \\
\hline & $\beta$ & Robust SE & $\beta$ & Robust SE & $\beta$ & Robust SE & $\beta$ & Robust SE \\
\hline \multicolumn{9}{|c|}{ Independent variables } \\
\hline $\mathrm{CT}$ & $0.0037 *$ & 0.0022 & $0.0045^{* *}$ & 0.0021 & $0.0045^{* *}$ & 0.0021 & $0.0038^{* *}$ & 0.0019 \\
\hline \multicolumn{9}{|c|}{$\begin{array}{l}\text { 1.Individual Level } \\
\text { (1) Personal variables }\end{array}$} \\
\hline Age & & & $-0.0776^{* *}$ & 0.0338 & $-0.0744 * *$ & 0.0340 & $-0.0674 * *$ & 0.0321 \\
\hline Age2 & & & $0.0008^{*}$ & 0.0004 & $0.0008^{*}$ & 0.0004 & $0.0007^{*}$ & 0.0004 \\
\hline Male & & & -0.0307 & 0.0821 & -0.0548 & 0.0814 & -0.0572 & 0.0813 \\
\hline Married & & & $0.2259 *$ & 0.1271 & 0.2068 & 0.1268 & $0.2215^{*}$ & 0.1196 \\
\hline Education year & & & 0.0391 & 0.1270 & 0.0316 & 0.1238 & 0.0530 & 0.1284 \\
\hline Education year2 & & & -0.0036 & 0.0052 & -0.0034 & 0.0051 & -0.0041 & 0.0052 \\
\hline Migrant & & & $-0.2830^{* *}$ & 0.1347 & $-0.2695^{* *}$ & 0.1317 & $-0.2767 * *$ & 0.1335 \\
\hline \multicolumn{9}{|l|}{ (2)Job-related traits } \\
\hline \multicolumn{9}{|c|}{ (1) Occupation categories: Ordinary worker(ref.) } \\
\hline Manager & & & 0.0837 & 0.0979 & 0.0954 & 0.0986 & 0.1128 & 0.1015 \\
\hline Skilled worker & & & $0.2996^{* *}$ & 0.1412 & $0.3049^{* *}$ & 0.1412 & $0.2987 * *$ & 0.1324 \\
\hline \multicolumn{9}{|l|}{ (2)Job conditions } \\
\hline Job strain & & & 0.0055 & 0.0397 & 0.0084 & 0.0396 & 0.0132 & 0.0406 \\
\hline Overtime & & & -0.0037 & 0.0092 & -0.0030 & 0.0090 & -0.0033 & 0.0085 \\
\hline Training & & & $0.0065 * *$ & 0.0031 & $0.0068 * *$ & 0.0032 & $0.0069 * *$ & 0.0031 \\
\hline Job tenure & & & 0.0084 & 0.0068 & 0.0040 & 0.0072 & 0.0044 & 0.0072 \\
\hline Job security & & & -0.0190 & 0.0449 & -0.0118 & 0.0452 & -0.0116 & 0.0462 \\
\hline Injure & & & $0.6757^{* *}$ & 0.2885 & $0.6637^{* *}$ & 0.2966 & $0.6272 * *$ & 0.3014 \\
\hline Log (wage) & & & $-0.2417 * *$ & 0.0952 & $-0.2323 * *$ & 0.0958 & $-0.3055^{* * *}$ & 0.1104 \\
\hline \multirow{2}{*}{\multicolumn{9}{|c|}{$\begin{array}{l}\text { 2.Company Level } \\
\text { (1)Company type: DPS(ref.) }\end{array}$}} \\
\hline & & & & & & & & \\
\hline SOE & & & & & $0.2035^{*}$ & 0.1181 & 0.1850 & 0.1210 \\
\hline FOE & & & & & -0.0865 & 0.1311 & -0.0898 & 0.1336 \\
\hline \multicolumn{9}{|l|}{ (2)Sector } \\
\hline Manufacture & & & & & -0.0833 & 0.0865 & -0.0831 & 0.0856 \\
\hline \multicolumn{9}{|l|}{ 3.City Level } \\
\hline First-tier city & & & & & & & 0.2359 & 0.2028 \\
\hline Second-tier city & & & & & & & 0.0290 & 0.1101 \\
\hline Constant & $0.8003^{* * *}$ & 0.0644 & $5.4678^{* * *}$ & 1.3393 & $5.3629 * * *$ & 1.3195 & $5.7611^{* * *}$ & 1.3048 \\
\hline LP & \multirow{2}{*}{\multicolumn{2}{|c|}{$\begin{array}{l}-7517.0 \\
4268\end{array}$}} & \multicolumn{2}{|c|}{-6736.6} & \multicolumn{2}{|c|}{-6707.5} & \multicolumn{2}{|c|}{-6678.0} \\
\hline$N$ & & & & 3855 & & 3849 & & 40 \\
\hline
\end{tabular}

Table 4 Robust Checks

\begin{tabular}{|c|c|c|c|c|c|c|c|c|c|c|c|c|}
\hline & \multicolumn{2}{|c|}{$\begin{array}{c}\text { Model(5) } \\
\text { Excluding Sickness } \\
\text { leave } \geq 30\end{array}$} & \multicolumn{2}{|c|}{$\begin{array}{c}\text { Model(6) } \\
\text { Sickness leave as } \\
\text { dummy variable }\end{array}$} & \multicolumn{2}{|c|}{$\begin{array}{c}\text { Model (7) } \\
\text { Commuting as } \\
\text { categorical variable }\end{array}$} & \multicolumn{2}{|c|}{$\begin{array}{l}\text { Model (8) } \\
\text { Excluding } \\
\text { Injure =1 }\end{array}$} & \multicolumn{2}{|c|}{$\begin{array}{c}\text { Model (9) } \\
\text { Excluding medical } \\
\text { cost }>10000\end{array}$} & \multicolumn{2}{|c|}{$\begin{array}{c}\text { Model (10) } \\
\text { Add transport } \\
\text { modes } \\
\text { variables } \\
\end{array}$} \\
\hline & $\beta$ & $\begin{array}{c}\text { Robust } \\
\text { SE }\end{array}$ & $\beta$ & Robust SE & $\beta$ & Robust SE & $\beta$ & $\begin{array}{c}\text { Robust } \\
\text { SE }\end{array}$ & $\beta$ & $\begin{array}{c}\text { Robust } \\
\text { SE }\end{array}$ & $\beta$ & $\begin{array}{c}\text { Robust } \\
\text { SE }\end{array}$ \\
\hline \multicolumn{13}{|c|}{ Independent variables } \\
\hline $\mathrm{CT}$ & $0.0024^{*}$ & 0.0012 & $0.0040^{* *}$ & 0.0018 & & & $0.0040^{* *}$ & 0.0019 & $0.0040^{* *}$ & 0.0019 & $0.0039^{* *}$ & 0.0020 \\
\hline $\begin{array}{l}\text { Mid- } \\
\text { commuter }\end{array}$ & & & & & 0.0987 & 0.1008 & & & & & & \\
\hline $\begin{array}{l}\text { Long- } \\
\text { commuters }\end{array}$ & & & & & $0.2475^{* *}$ & 0.1136 & & & & & & \\
\hline Constant & $3.8646^{* * *}$ & 0.8510 & $-2.9063^{* *}$ & 1.1485 & $5.9937^{* * *}$ & 1.3136 & $6.0289^{* * *}$ & 1.3064 & $5.0493^{* * *}$ & 1.1647 & $5.6020^{* * *}$ & 1.2894 \\
\hline$N$ & \multicolumn{2}{|c|}{3802} & \multicolumn{2}{|c|}{3840} & \multicolumn{2}{|c|}{3850} & \multicolumn{2}{|c|}{3747} & \multicolumn{2}{|c|}{3742} & \multicolumn{2}{|c|}{3840} \\
\hline
\end{tabular}

Model: Zero-inflated negative binomial regressions are used in all models except for Model (6)(Logit)

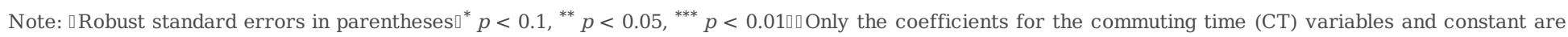
reported in NB model. aLike in the main tables, the following control variables are included: individual level, company level and city level.

Table 5 Mechanism analysis: health outcomes and work effort

\begin{tabular}{|c|c|c|c|c|c|c|c|c|c|c|c|c|c|c|}
\hline & \multicolumn{2}{|c|}{$\begin{array}{c}\text { Model (11) } \\
\text { Self-rated health }\end{array}$} & \multicolumn{2}{|c|}{$\begin{array}{l}\text { Model (12) } \\
\text { Depression }\end{array}$} & \multicolumn{2}{|c|}{$\begin{array}{c}\text { Model (13) } \\
\text { BMI }\end{array}$} & \multicolumn{2}{|c|}{$\begin{array}{c}\text { Model (14) } \\
\text { Obesity (0-1) }\end{array}$} & \multicolumn{2}{|c|}{$\begin{array}{c}\text { Model (15) } \\
\text { Medical cost }\end{array}$} & \multicolumn{2}{|c|}{$\begin{array}{c}\text { Model (16) } \\
\text { Overtime } \\
\text { Duration }\end{array}$} & \multicolumn{2}{|c|}{$\begin{array}{c}\text { Model(17) } \\
\text { Overtime } \\
\text { Dummy }\end{array}$} \\
\hline & $\beta$ & $\begin{array}{c}\text { Robust } \\
\text { SE }\end{array}$ & $\beta$ & $\begin{array}{c}\text { Robust } \\
\text { SE }\end{array}$ & $\beta$ & $\begin{array}{c}\text { Robust } \\
\text { SE }\end{array}$ & $\beta$ & $\begin{array}{c}\text { Robust } \\
\text { SE }\end{array}$ & $\beta$ & $\begin{array}{c}\text { Robust } \\
\text { SE }\end{array}$ & $\beta$ & $\begin{array}{c}\text { Robust } \\
\text { SE }\end{array}$ & $\beta$ & $\begin{array}{c}\text { Robust } \\
\text { SE }\end{array}$ \\
\hline CT & $-0.0012^{* *}$ & 0.0006 & $0.0017^{* *}$ & 0.0007 & $0.0096^{\text {*** }}$ & 0.0025 & $0.0057^{* * *}$ & 0.0019 & $0.0026^{*}$ & 0.0015 & -0.0005 & 0.0048 & -0.0024 & 0.0018 \\
\hline Constant & $4.1849^{* * *}$ & 0.3363 & $3.139^{* * *}$ & 0.4514 & $17.23^{* * *}$ & 1.5696 & $-3.749^{* * *}$ & 1.235 & $3.564^{* * *}$ & 0.9160 & 4.2111 & 3.099 & $8.076^{* * *}$ & 1.3026 \\
\hline $\mathrm{R}^{2}$ & \multicolumn{2}{|c|}{0.0887} & \multicolumn{2}{|c|}{0.0776} & \multicolumn{2}{|c|}{0.2033} & \multicolumn{2}{|c|}{3849} & \multicolumn{2}{|c|}{0.1052} & \multicolumn{2}{|c|}{0.0484} & \multicolumn{2}{|c|}{0.1000} \\
\hline
\end{tabular}




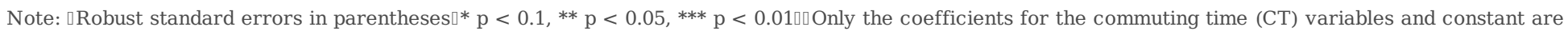
reported. $\square$ Like in the main tables, the following control variables are included: individual-level, company-level and city-level.

Table 6 Heterogeneous effects with respect to hukou status, gender, transportation modes, cities and enterprises

\begin{tabular}{|c|c|c|c|c|c|c|c|c|c|c|c|c|}
\hline & \multicolumn{2}{|c|}{ Model(18a)Migrant=1 } & \multicolumn{2}{|c|}{$\begin{array}{c}\text { Model (18b) } \\
\text { Migrant=0 }\end{array}$} & \multicolumn{2}{|c|}{$\begin{array}{c}\text { Model (19a) } \\
\text { Male }=1\end{array}$} & \multicolumn{2}{|c|}{$\begin{array}{c}\text { Model (19b) } \\
\text { Male }=0\end{array}$} & \multicolumn{2}{|c|}{$\begin{array}{c}\text { Model (20a) Active } \\
\text { mode }=1\end{array}$} & \multicolumn{2}{|c|}{$\begin{array}{c}\text { Model }(20 \mathrm{~b}) \\
\text { Active mode }=0\end{array}$} \\
\hline & $\beta$ & Robust SE & $\beta$ & $\begin{array}{c}\text { Robust } \\
\text { SE }\end{array}$ & $\beta$ & $\begin{array}{c}\text { Robust } \\
\text { SE }\end{array}$ & $\beta$ & $\begin{array}{c}\text { Robust } \\
\text { SE }\end{array}$ & $\beta$ & Robust SE & $\beta$ & Robust SE \\
\hline $\mathrm{CT}$ & 0.0004 & 0.0036 & $0.0046^{* *}$ & 0.0021 & -0.0010 & 0.0024 & $0.0054^{* *}$ & 0.0022 & 0.0056 & 0.0044 & 0.0026 & 0.0021 \\
\hline Constant & $8.499^{* * *}$ & 2.6496 & $6.305^{* * *}$ & 1.3987 & $4.123^{* *}$ & 1.9518 & $6.3274^{* * *}$ & 0.6407 & $5.9521 * * *$ & 2.2543 & $5.7538 * * *$ & 1.5139 \\
\hline LP & \multicolumn{2}{|c|}{-1307.955} & \multicolumn{2}{|c|}{-5330.877} & \multicolumn{2}{|c|}{-2817.721} & \multicolumn{2}{|c|}{-3819.681} & \multicolumn{2}{|c|}{-2064.543} & \multicolumn{2}{|c|}{-4572.777} \\
\hline \multirow[t]{4}{*}{$\mathrm{N}$} & \multicolumn{2}{|c|}{797} & \multicolumn{2}{|c|}{3043} & \multicolumn{2}{|c|}{1748} & \multicolumn{2}{|c|}{2092} & \multicolumn{2}{|c|}{1273} & \multicolumn{2}{|c|}{2567} \\
\hline & \multicolumn{2}{|c|}{ Model (21a) } & \multicolumn{2}{|c|}{ Model (21b) } & \multicolumn{2}{|c|}{ Model (21c) } & \multicolumn{2}{|c|}{ Model (22a) } & \multicolumn{2}{|c|}{ Model (22b) } & \multicolumn{2}{|c|}{ Model (22c) } \\
\hline & \multicolumn{2}{|c|}{ First-tier city } & \multicolumn{2}{|c|}{ Second-tier city } & \multicolumn{2}{|c|}{ Third-tier city } & \multicolumn{2}{|c|}{$\begin{array}{c}\text { State-owned } \\
\text { Enterprise(SOE) }\end{array}$} & \multicolumn{2}{|c|}{$\begin{array}{l}\text { Foreign-owned } \\
\text { enterprise(FOE) }\end{array}$} & \multicolumn{2}{|c|}{$\begin{array}{l}\text { Domestic private } \\
\text { enterprises(DPE) }\end{array}$} \\
\hline & $\beta$ & Robust SE & $\beta$ & $\begin{array}{c}\text { Robust } \\
\text { SE }\end{array}$ & $\beta$ & $\begin{array}{c}\text { Robust } \\
\text { SE }\end{array}$ & $\beta$ & $\begin{array}{c}\text { Robust } \\
\text { SE }\end{array}$ & $\beta$ & Robust SE & $\beta$ & Robust SE \\
\hline CT & $0.0051 *$ & 0.0028 & 0.0020 & 0.0025 & -0.0059 & 0.0076 & -0.0034 & 0.0048 & $-0.012 * * *$ & 0.0044 & $0.0054^{* *}$ & 0.0021 \\
\hline LP & \multicolumn{2}{|c|}{-1181.867} & \multicolumn{2}{|c|}{-4026.74} & \multicolumn{2}{|c|}{-1351.594} & \multicolumn{2}{|c|}{-894.8259} & \multicolumn{2}{|c|}{-324.5178} & & 7.72 \\
\hline $\mathrm{N}$ & & 13 & & & & & 58 & & & 13 & & 39 \\
\hline
\end{tabular}

Model: Zero-inflated negative binomial regressions are used in all models.

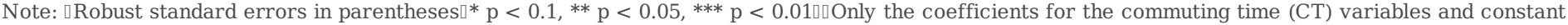
are reported in NB model. 口Like in the main tables, the following control variables are included: individual level, company level and city level. 